\title{
Interactive comment on "Deforestation decreases resistance of simulated Easter Island climate to drought" by Alexander Lemburg et al.
}

\section{Anonymous Referee \#2}

Received and published: 25 August 2016

This work examined the sensitivity of surface variables (temperature, precipitation) to changes in land surface conditions (vegetation cover, soil moisture) over Easter Island using a limited-area mesoscale numerical weather model. The authors found that the top-soil layer of a bare-soil Easter Island becomes much warmer with almost doubled surface wind speeds when compared to a fully tree-covered Easter Island. The authors suggested that the climate of a deforested Easter Island appears to be more prone to drought than a forested Easter Island due to (a) evapotranspiration decreases much more slowly over a forested island and (b) a tree-covered island triggers convective precipitation much more efficiently because of higher surface roughness and stronger sensible heat flux. The idea of this work is good; however, I have major concerns about the methodology applied in the work and the relevance to the past climate as well as the content of the manuscript. Please refer to my major concerns below. 
(1) Climate is the averaged conditions over a long term during which the atmosphere affects the land surface and the land surface affects the atmosphere. This two-way feedback acts on various temporal and spatial scales but generally the impact of land surface on atmosphere becomes significant over a long term. In this work, the authors chose 14 weather episodes and ran the limited-area weather model for the duration of the weather episodes and only in one case for an extended period of 52 days. I am not at all convinced that these weather episodes represent the climate of Easter Island and that the simulated states reflect the two-way feedback between the atmosphere and the land surface. In order to understand the impact of the land surface conditions on the climate of Easter Island, the authors really need to run their model for multiple years (at least two to three years) for each initial condition with carefully designed model experiment and then examine the temporal and spatial distributions and average conditions over the simulation period. For the initial soil moisture conditions, the authors may only need to choose the low soil moisture case (10\%) and the high soil moisture case $(80 \%)$ while for the weather cases, the authors may just need to choose one or two weather episodes from each category: clear sky, large scale, and convective precipitation. This way the model runs can become much more manageable and the model simulations would be more representative.

(2) The main purpose of this study is to investigate the impact of deforestation that happened several hundred years ago on the near-surface climate of Easter Island. The authors chose the weather episodes that occurred primarily in this and last decade. This is okay as long as the authors clearly demonstrate the relevance of these weather episodes to the weather conditions that may have prevailed over Easter Island several hundred years ago. The authors put together a section trying to provide some evidence by looking at the present-day climate using the ERA-Interim reanalysis data and the surface measurements at the Mataveri Airport but it is not convincing. What if the mean or the extreme climate over Easter Island several hundred years ago was different from the present-day climate? There are paleoclimate model simulations that people have done and the authors should make use of these simulations and compare and make 
sure that the present-day climate over Easter Island is not different from that several hundred years ago. Otherwise, using the present-day climate to shed light on what may have happened long time ago could lead to misleading results.

(3) The authors used the limited-area COSMO model to understand the impact of deforestation on the near-surface climate of Easter Island. The model does seem to be well documented but the authors did not provide any evaluation and discussions of the model performance in resolving and representing the Easter Island's climate even in the present days. It is really important for the authors to first show that the model is doing a reasonably good job in simulating the local climate before using the model for further application. There may not be a whole lot observations to compare with over Easter Island but at least there are measurements of temperature, winds, precipitation and likely humidity from the airport and the authors can also make use of satellite measurements to assess the model performance. Once the authors demonstrate that the model performance is acceptable in the present-day climate and that the climate several hundred years ago is not different from the present-day climate, then the authors can safely use the model to study the impact of deforestation on the near-surface climate of Easter Island that may have happened at that time.

(4) Admittedly the authors did a lot of work with conducting the sensitivity runs and analyzing the model simulations but the manuscript was poorly written. For one, the introduction does not cite and discuss any of the published papers on the effects of land surface changes on the climate. This topic is not new and there are a wealth of published papers on this topic that the authors fail to review and mention and contrast. The authors really need to point out in the introduction what differs this work from the published papers and why it is important. Simply applying a different model over a different place is not enough. Another area of improvement is the description of the model. The authors described the model to a great extent in the supplementary material but remember that the readers normally don't read the supplementary material. Thus, a better way to do is to move some of the details back to the main text while still

\section{CPD}

Interactive comment

\section{C3}

Printer-friendly version

Discussion paper

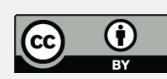


keeping the model section brief or add an appendix to the main text.

Interactive comment on Clim. Past Discuss., doi:10.5194/cp-2016-68, 2016.
CPD

Interactive comment 